\title{
O USO DAS NOVAS TECNOLOGIAS NAS AULAS DE LÍNGUA INGLESA: UM RELATO A PARTIR DAS PRÁTICAS DE ESTÁGIO SUPERVISIONADO.
}

Mayara Marques de Santana, Universidade Federal de Campina Grande (UFCG), mayaraxmarques@hotmail.com

Érica Nayara da Silva Costa, Universidade Federal de Campina Grande (UFCG), ekynay@gmail.com

Fabione Gomes da Silva, Universidade Federal de Campina Grande (UFCG) gomesfabione@hotmail.com

\begin{abstract}
RESUMO
O presente artigo foi elaborado no intuito de relatar sobre a importância do uso das Tecnologias da Informação e da Comunicação (TICs) na sala de aula a partir de experiências vivenciadas durante a etapa de Estágio Curricular Supervisionado em Língua Inglesa. Utilizando-se então da abordagem qualitativa apoiada na pesquisa documental buscou-se também destacar a importância do Estágio Supervisionado como peça fundamental para a formação crítica do graduando. Vale ressaltar que esse texto foi ancorado nas orientações advindas dos documentos oficiais que regulamentam a educação no Brasil e, também em teóricos como Perrenoud (2000) e Ferreira (2010) que abordam o uso da tecnologia como fim educacional, Leffa (2008) e Jorge (2009) que trabalham com o ensino de língua inglesa e Silva e Miranda (2008) e Pimenta (2006) que apontam a relevância do Estágio Supervisionado. Por fim, buscou-se então contribuir, à medida que oferece uma reflexão acerca do uso dessas tecnologias e de como elas podem auxiliar no processo de ensino/aprendizagem do discente.
\end{abstract}

PALAVRAS-CHAVES: tecnologia; língua inglesa; estágio supervisionado.

\section{THE USE OF NEW TECHNOLOGIES IN ENGLISH LANGUAGE CLASS: A REPORT FROM THE PRACTICES OF SUPERVISED STAGE}

\begin{abstract}
This article was elaborated in order to reporta bout the Information and Communication Technologies in the classroom, based one experiences during the stage of Supervised Curriculum in English Language. Using the qualitative and anchored in the oficial documents of education, and also by theorists who address the use of technology as na educational end,sought
\end{abstract}


to contribute, as workoffers a reflection a bout their use in the teaching/ learning process of the student.

KEYWORDS:technologies; English language; supervised internship.

\section{EL USO DE LAS NUEVAS TECNOLOGÍAS EN LAS CLASES DE LENGUA INGLESA: UN RELATO A PARTIR DE LAS PRÁCTICAS DE PASANTÍA SUPERVISADA.}

\section{RESUMEN}

Este artículo tiene el propósito de relatar sobre las Tecnologías de la Información y de la Comunicación en el aula en las experiencias de la Pasantía Curricular Supervisada. Utilizando el abordaje cualitativo y anclado en los documentos oficiales de la educación, y también en teóricos que abordan el uso de la tecnología como finalidad educacional, se buscó contribuir, a medida que ofrece una reflexión acerca del uso de ellas en el proceso de enseñanza/aprendizaje del estudiante.

PALABRAS CLAVES: tecnología; lengua inglesa; pasantía supervisada.

\section{INTRODUÇÃO}

A Revolução Tecnológica tem oportunizado mudanças sociais, similarmente no contexto da educação, visto as oportunidades oriundas da inclusão das TICs (Tecnologias da Informação e da Comunicação) na sala de aula. No caso de ensino de línguas estrangeiras, percebe-se que a utilização das ferramentas tecnológicas vem ampliando as possibilidades de aprendizagem e o desenvolvimento das habilidades comunicativas de maneira significativa.

Este trabalho tem como objetivo geral relatar o uso das Novas Tecnologias na prática docente durante a etapa de Estágio Curricular Supervisionado em Língua Inglesa, tendo como objeto de estudo o gênero textual Relatório de Estágio. Os nossos objetivos específicos são: analisar o contexto de uso das Novas Tecnologias na Educação Básica;destacar a importância do Estágio Curricular Supervisionado em Língua Inglesa; erelatar experiências de prática docente usando as Novas Tecnologias como ferramentas auxiliares no processo de ensino/aprendizagem de Língua Inglesa durante a etapa de Estágio Supervisionado. 
Buscamos com esse estudo contribuir para a reflexão social e educacional no processo de ensino/aprendizagem de língua inglesa, oferecendo um tipo de compreensão, de como as novas tecnologias podem ser utilizadas para desenvolver a construção do saber discente, e de como o Estágio Curricular Supervisionado se constitui em uma etapa crucial para o aperfeiçoamento profissional do aluno de licenciatura. O estágio é caracterizado como um espaço de experiências, estudos, reflexões e propostas sobre a prática de ensinar, pois é nesse momento que o graduando assume uma postura crítica questionando sua abordagem, como bem coloca Nascimento e Barbosa (2014, p. 4): “A síntese reflexiva é o momento em que o estagiário apresenta, por escrito e com embasamentos teóricos, os desafios e as aprendizagens vivenciadas no estágio".

O ensino de língua inglesa tem papel fundamental no desenvolvimento do indivíduo dentro da sociedade, afim de contribuir para o seu despertar em relação as necessidades de construção e formação de cidadão. No entanto, o espaço da língua inglesa no currículo escolar brasileiro ainda é mínimo em relação às outras disciplinas, geralmente são ministradas apenas duas aulas por semana, apresentando assim uma carga horária limitada para uma eficácia do aprendizado. Nesse sentido Jorge (2009, p. 162) destaca que "a língua estrangeira é um componente essencial para a educação básica dos brasileiros e precisa ser considerada como uma área de conhecimento tão importante como outra qualquer."

Dessa forma, aliando teoria e prática, tendo como fundamentações principais os documentos oficiais que regulamo ensino de língua estrangeira e o uso das novas tecnologias em sala de aula, adotamos como procedimentos metodológicos, o paradigma interpretativista (qualitativo), já que considera condições específicas do sujeito em contraponto com o paradigma (positivista) que se preocupa com números de intensidade e frequência. Segundo Costa, "a abordagem qualitativa busca significados, não exige representatividade amostral, trabalha com pressupostos" (2015, p. 38).Nesta pesquisa foi utilizada a abordagem qualitativa apoiada na pesquisa documental e, aliando teoria e prática, temos como fundamentações principais os documentos oficiais que regulamo ensino de língua estrangeira e o uso das novas tecnologias em sala de aula. 
Para a realização desse estudo, foram utilizados como aporte teórico os documentos oficiais que regem a educação: Parâmetros Curriculares Nacionais (PCN);Parâmetros Curriculares Nacionais do Ensino Médio(PCNEM); Orientações Educacionais Complementares aos Parâmetros Curriculares Nacionais(PCN+); Orientações Curriculares para o Ensino Médio(OCEM); Base Nacional Comum Curricular(BCNN). E para tratar o ensino de língua inglesa foram usados os estudos de Leffa (2008), Martinez (2009) e Jorge (2009). E refletindo sobre o Estágio Supervisionado nos embasamosem Silva e Miranda (2008); Barreiro e Gebran (2006); Silva e Turbin (2012) e Pimenta (2006).

O nosso artigo está disposto da seguinte maneira: No capítulo 1, intitulado:“As novas tecnologias no contexto educacional do Brasil" trazem uma discussão acerca dos documentos oficiais da educação. No capítulo 2, "O estágio supervisionado e sua importância na formação docente", buscamos discorrer sobre a necessidade do estágio para a formação docente. E no capítulo 3, "Relato de experiência do estágio supervisionado", apresentaremos algumas experiências vividas em sala de aula. Na sequência a conclusão, abstract, resumen e referências bibliográficas.

\section{AS NOVAS TECNOLOGIAS NO CONTEXTO EDUCACIONAL DO BRASIL: PCN; PCNEM; PCN+; OCEM; BCNN}

O ensino de língua estrangeira é regido por documentos utilizados como referências educacionais, tais como os Parâmetros Curriculares Nacionais (PCN),Parâmetros Curriculares Nacionais do Ensino Médio (PCNEM), Orientações Educacionais Complementares aos Parâmetros Curriculares Nacionais (PCN+), Orientações Curriculares para o Ensino Médio (OCEM), Base Nacional Comum Curricular (BNCC), que constituem importantes direções para a educação, tendo assim uma função relevante no planejamento e prática pedagógica dos profissionais da educação.

Tratando dos PCN, o documento enfatiza o ensino sociointeracionista, que busca o desenvolvimento discursivo do aprendiz. Nesse sentido, "essa construção passa pelo envolvimento do aluno com os processos sociais de criar significados por intermédio da utilização de uma língua estrangeira. " (PCN, 1998, p. 19). Nos PCN, encontramos justificadas as escolhas por uma abordagem teórico-metodológicaqueprioriza o 
desenvolvimento da capacidade cognitiva do aprendiz, com vistas à uma formação cidadã, a partir de práticas de leituras situadas.

Porém este documento não descarta a possibilidade de ser desenvolvidas as outras habilidades comunicativas, tais como a produção oral, escrita e a compreensão auditiva. Portanto, é enfatizado que "a leitura tem função primordial na escola e aprender a ler em outra língua pode colaborar no desempenho do aluno como leitor em sua língua materna" (PCN, 1998, p. 20).

Já os PCNEM orientam que o ensino não seja voltado apenas para uma aprendizagem estática, mas desenvolva competências mais abrangentes que envolvam o conhecimento e uso da língua estrangeira como veículo de entrada para outras culturas, assim como também "entender os princípios das tecnologias da comunicação e da informação, associá-las aos conhecimentos científicos, às linguagens que lhe dão suporte e aos problemas que se propõem a solucionar." (PCNEM, 2000, p. 11)

Outro documento com relação às políticas educacionais para o ensino de línguas estrangeiras sãoos $\mathrm{PCN}+$, também criado no intuito de oferecer um complemento para esse fim. Nele é ressaltado que "o foco do aprendizado deve centrar-se na [...] leitura e a compreensão de textos verbais orais e escritos" (PCN+, 2002, p. 94). Além disso, o documento reforça a importância da disciplina de língua estrangeiracomo meio de auxílio para demais disciplinas curriculares, pois pode oferecer "múltiplos suportes para várias atividades e projetos" (PCN+, 2002, p. 94).

Corroborando com esse entendimento, a Base Nacional Comum Curricular(BNCC)em sua forma ainda preliminar de implementação, afirma que "o estudo da língua inglesa possibilita aos alunos ampliar horizontes de comunicação e de intercâmbio cultural, científico e acadêmico" (BNCC, 2015, p. 199) oportunizando assim a formação do pensamento crítico do educando.

Semelhantemente, as Orientações Curriculares para o Ensino Médio (OCEM) também se constituem em uma referência educacional, ao contribuir com uma abordagem reflexiva e inclusiva "no que se refere às habilidades a serem desenvolvidas no ensino de Línguas Estrangeiras no ensino médio, este documento focaliza a leitura, a prática escrita e a comunicação oral contextualizadas" (OCEM, 2006, p. 87). Segundo Martinez, "ensinar é pôr em contato, pelo próprio ato, sistemas linguísticos, e as 
variáveis da situação refletem-se tanto sobre a psicologia do indivíduo falante quanto sobre o funcionamento social em geral"(2009, p. 15).

Ainda acerca dessa questão, é visto que o aprendizado de uma língua ocorre quando o aprendiz está inserido em um contexto histórico, cultural e social, fatores queinfluenciam diretamente nesse processo, e devem ser considerados importantes para ajudar a promover a aprendizagem. Dessa forma Leffa (2008, p. 354) enfatiza que o processo de formação docente envolva“o domínio de diferentes áreas de conhecimento, incluindo o domínio da língua que ensina, e o domínio da ação pedagógica necessária para fazer a aprendizagem da língua acontecer na sala de aula. ". Tendo em vista o contexto pragmático-discursivo do discente, observa-se uma carência nadidática das aulas de línguas em meio as novas tecnologias, pois as novas ferramentas tecnológicas aumentariam as possibilidades de comunicação.

Com a expansão do fenômeno da Globalização, sobretudo com o advento das chamadas TICs (Tecnologia da Informação e da Comunicação), oportunizaram-se mais possibilidades de trocas comunicativas entre comunidades linguísticas distintas, tendo o Inglês como Língua oficial para esse fim. Atualmente, aprender a língua inglesa é fundamental para aqueles que buscam uma carreira promissora pelas vantagens proporcionadas, já que os currículos para um bom emprego requisitam o conhecimento de uma língua estrangeira, de preferência o inglês. Além de tudo, a facilidade de acesso à informação, por conseguinte a influência por meio da internet contribui para a interação e a real comunicação com falantes nativos ou não da língua inglesa. De acordo com Castells:

As novas tecnologias da informação difundiram-se pelo globo com a velocidade da luz em menos de duas décadas, entre meados dos anos 70 e 90, por meio deuma lógica que ao meu ver, é a característica dessa revolução tecnológica: aplicação imediata no próprio desenvolvimento da tecnologia gerada, conectando o mundo através da tecnologia da informação. (CASTELLS, 2006, apud FERREIRA, 2010, p. 56)

De outro modo, o avanço tecnológico introduziu novas ferramentas que auxiliam no ensino de língua inglesa em nível global, tais como a tv, o rádio, smartphone, tablets, computadores, projetores, e principalmente a internet, que alcança vários níveis de comunicação, comportando-se como um instrumento de grande importância no ensino de línguas, pois fornece diversos subsídios que estabelecem a comunicação com 
indivíduos do idioma alvo. Portanto, cabe a escola integrar esse contexto tecnológico na prática pedagógica afim de ganhar um sentido educacional significativo, nesse sentido Ferreira (2010, p. 59) enfatizaque, "se a escola não inclui as TIC como ferramenta em sua prática pedagógica, ela está na contramão da história, uma vez que alheia ao seu tempo, contribui para a exclusão social do aprendiz".

Isto é, a escola precisa conectar a rotina do aluno com os conteúdos e, adequarse à nova realidade tecnológica, onde os discentes estão diariamente conectados e recebendo muita informação à nível global de forma muito rápida, contexto esse que a língua inglesa estar presente intrinsicamente. Por isso os alunos precisam ter consciência do valor educativo no aprendizado da língua inglesa, para que possam, de acordo com Jorge(2009, p. 164 e 165) "refletir sobre a língua materna e cultura materna e aprender sobre a diversidade cultural que existe no mundo e no seu próprio país". FORMAÇÃODOCENTE

O Estágio Supervisionado é fundamental para a formação docente, pois se destaca como um processo de aprendizagem que relaciona teoria e prática em um contexto real, oportunizando ao graduando uma compreensão de seu futuro ambiente de atuação profissional. A esse respeito, Silva e Miranda (2008, p. 121) afirmam que o aluno-estagiário deve "pensar o estágio como uma possibilidade de formação, onde se pudesse pensar a teoria e prática como unidade, em que o centro de atenção fosse a emergência dos sentidos para a formação docente."

Observa-se que essa etapa, também se comporta como um momento de reflexão, em que o docente em formação toma uma posição crítica mediante os conhecimentos fornecidos pela instituição formadora e o próprio espaço de aplicação desses saberes. Barreiro e Gebran (2006, p. 20) compreendem o estágio como um “locus de reflexão e formação da identidade ao propiciar embates no decorrer das ações vivenciadas pelos alunos, desenvolvidas numa perspectiva reflexiva e crítica". Corroborando, as autoras Silva e Miranda apontam que os estagiários "passam a ser entendidos como autores/autoras pedagógicos/as em busca do questionamento, da compreensão, acerca do modo como o conhecimento é produzido e distribuído" (2008, p. 125). 
Além disso, esse processo do estágio finaliza-se com uma produção escrita, resultado das observações e prática de ensino.De acordo com os autores Silva e Turbin (2012, p. 18): “A produção de relatórios se configura como a primeira experiência de uso da escrita reflexiva sobre a prática profissional, ou seja, como instrumento de mediação para fortalecer a formação do professor. " Esse registro de experiências vividas no ambiente educacional, serve também como material de consulta para futuros estagiários, comportando-se como documentos de experiências adquiridas durante tal etapa.

A prática docente deve levar em conta o contexto social e histórico do aprendiz, desse modo, o conhecimento de mundo é considerado como parte de um aprendizado eficaz na construção da capacidade cognitiva do aluno. Nesse sentido a formação de professores necessita estar ancoradaem"paradigmas orientados por um ensino crítico, de modo que a prática docente seja decorrente não só da compreensão dos processos de ensino-aprendizagem, como também do contexto social em que ela acontece." (BARREIRO; GEBRAN, 2006, p. 36). Para definir a atividade docente, Pimenta enfatiza:

\begin{abstract}
A essência da atividade (prática) do professor é o ensinoaprendizagem. Ou seja, é o conhecimento técnico prático, de como garantir que a aprendizagem se realize como consequência da atividade de ensinar. Envolve, portanto, o conhecimento do ob, o estabelecimento de finalidades e a intervenção no objeto para que a realidade (não-aprendizagem) seja transformada, enquanto realidade social. (PIMENTA, 2006, p. 83)
\end{abstract}

Ainda enfatizando a questão do professor como agente reflexivo no contexto escolar, os autoresPimenta e Ghedin (2002, p. 20) destacam que "é possível olhar retrospectivamente sobrea reflexão na ação. Após a aula, o professor pode pensar no que aconteceu no que observou, no significado que lhe deu e na eventual adoção de sentidos. "

\title{
3. RELATO DE EXPERIÊNCIA DO ESTÁGIOSUPERVISIONADO
}


Durante o período da ministração de aulas no estágio supervisionado, o uso das TICs se constituiu em um suporte eficaz para o ensino da língua inglesa, e o celular foi então o principal recurso adotado para tal prática, visto que a maioria dos alunos da sala dispunha do aparelho e o levavam para a escola. Essa prática se deu através do uso de aplicativos instalados no celular, como por exemplo, o Practice English Conversation, que tem por objetivo a conversação usando as quatro habilidades comunicativas: listening, reading, writing, speaking. $\mathrm{O}$ aplicativo dispunha de textos que solicitavam a leitura em voz alta e havia nele também a opção de gravar essa leitura, exercitando assim as habilidades do readinge speaking. Dispunha também de atividades de interpretação desses textos, onde o aluno deveria digitar as respostas, usando assim o writing e, outra opção era ouvir (listening) através do aplicativo a leitura do texto e da atividade.

Mesmo com certa resistência por parte de alguns alunos, pois relataram não estar habituados a esse tipo de aula, a turma, de modo geral participou, afirmando ter gostado das aulas mais dinamizadas e se mostraram mais motivados no estudo da língua inglesa. Foi possível constatar então que "as TICs transformam sobremaneira, não só nossas maneiras de comunicar, mas também de trabalhar, de decidir, de pensar" Perrenoud (2000, p. 71). Então o uso do celular pode ser útil para as aulas, despertando assim o interesse dos alunos e contribuindo para o aprendizado, o autor ainda acrescenta:

\begin{abstract}
As novas tecnologias podem reforçar a contribuição dos trabalhos pedagógicos e didáticos contemporâneos, pois permitem que sejam criadas situações de aprendizagem ricas, complexas, diversificadas, por meio de uma divisão de trabalho que não faz mais com que todo o investimento repouse sobre o professor, uma vez que tanto a informação quanto a dimensão interativa são assumidas pelos produtores dos instrumentos. (PERRENOUD, 2000, p. 139)
\end{abstract}

Nas aulas seguintes, o recurso de mídia Data show foi utilizado para uma apresentação de slides, com foco na importância de estudar língua inglesa. Nos slides foram trabalhadosmemes da internet, como o Bode Gaiato, que abordavam a língua inglesa de maneira divertida. Através desses memes, foi feita uma reflexão de como o inglês está presente no dia a dia, exemplificando com situações corriqueiras, tal como ir ao Shopping Center, e passar por situações que envolviam o conhecimento da língua 
inglesa. Sendo discutida ainda, a globalização e suas consequências, a exemplo da conexão da internet.

Durante a apresentação dos slides, também foram mencionados aplicativos que auxiliam no aprendizado de línguas, a exemplo do Duolingo e o Tandem, o primeiro trata-se de um aplicativo voltado para o ensino de língua inglesa de modo dinâmico, já o segundo é uma espécie de rede social direcionada ao aprendizado de um novo idioma a nível global.

Por conseguinte, foram mostradas palavras da língua inglesa que estão presentes na fala dos brasileiros, tais como: shopping center, vídeo game, pen drive, hamburger, ketchup, entre outras.E os discentes foram questionados sobre quais outras palavras eles conheciam, constituindo-se em um momento proveitoso porque houve um envolvimento da sala com o tema. Após, trabalhou-se uma tabela com frases nordestinas, retirada da rede social Facebook, assimiladas com frases da língua inglesa, foi um momento divertido, porque eram frases do contexto dos alunos.

Além disso, nas ministraçõesfoi feita uma atividade com a música "Samba do Approach", sendo aproveitada especialmente para o desenvolvimento do vocabulário dos alunos de maneira dinâmica, todavia foi utilizado primeiramente o vídeo da música, para assim também trabalhar a habilidade comunicativa da compreensão (listening), e depois com a letra impressa os discentes utilizaram a estratégias de leitura skimming para buscar o assunto geral da música, em sequência foi estabelecida a discussão sobre o estrangeirismo presente na letra, depois na exploração do vocabulário os estudantes relacionaram imagens contidas nos slides com as palavras em língua inglesa presentes na música.

\section{CONCLUSÃO}

Concluiu-se, portanto que as TICs se constituem em uma importante ferramenta para auxiliar no processo de ensino/aprendizagem de língua inglesa dos discentes. E uma vantagem de se trabalhar com as TICs é a possibilidade que ela oferece indo desde o uso de aplicativos que visam o exercício das habilidades comunicativas, até outros recursos como reprodutores de vídeo e slides, proporcionando uma aula mais interativa e dinamizada, podendo assim estimular os discentes a estudar a língua inglesa.Nesse 
sentido, o Estágio Supervisionadotambém pode ser um momento propício para a aplicação dessas tecnologias, caracterizando-se como uma oportunidade de adentrar no ambiente escolar e conhecer a realidade dos alunos.

\section{REFERÊNCIAS:}

BARREIRO, I. M. F; GEBRAN, R, A. Prática de Ensino e Estágio Supervisionado na Formação de Professores. São Paulo: Avercamp, 2006.

BRASIL. Ministério da Educação. Base Nacional Comum Curricular - Documento preliminar. MEC. Brasília, DF, 2015.

BRASIL. Ministério da Educação. Secretaria de Educação Média e Tecnológica. Parâmetros Curriculares Nacionais (Ensino Médio). Brasília: MEC, 2000.

BRASIL. Ministério da Educação. Secretaria da Educação Média e Tecnológica. Parâmetros Curriculares Nacionais + $(\mathrm{PCN}+)$ - Ciências da Natureza e suas Tecnologias. Brasília: MEC, 2002.

BRASIL, Ministério da Educação. Secretaria de Educação Básica. Orientações Curriculares para o Ensino Médio: linguagens, códigos e suas tecnologias. Brasília: SEB/MEC, $2006 . \quad$ Disponível em :<http://www.letras.ufmg.br/profs/reinildes/dados/arquivos/ocem.pdf.> . Acesso em: 08. Agos.t. 2017. Às $13 \mathrm{~h} 00$.

CASTELLS, M. A sociedade em rede. (A era da informação: economia, sociedade e cultura. In: FERREIRA, Edilene Lucena. $O$ uso pedagógico da informação e da comunicação no ensino e na aprendizagem de língua inglesa. 2010. 126 f. Dissertação (Mestrado). Curso de Mestrado do Programa de Pós-graduação em Educação. UFPB/BC. João Pessoa, 2010. Disponível em: <http://tede.biblioteca.ufpb.br:8080/bitstream/tede/4924/1/arquivototal.pdf>. Acesso em 08. Agost. 2017. Às 16h30min.

COSTA, M. A. F. da; COSTA; Maria de Fátima Barrozo da. Projeto de pesquisa: entenda e faça. 6. ed. - Petrópolis, RJ : Vozes, 2015.

FERREIRA, E. L. O uso pedagógico da informação e da comunicação no ensino e na aprendizagem de língua inglesa. 2010. 126 f. Dissertação (Mestrado). Curso de Mestrado do Programa de Pós-graduação em Educação. UFPB/BC. João Pessoa, 2010. Disponível

em: <http://tede.biblioteca.ufpb.br:8080/bitstream/tede/4924/1/arquivototal.pdf>. Acesso em 08. Agost. 2017. Às 16:00. 
JORGE, M. L. dos S..Preconceito contra o ensino de língua estrangeira na rede pública.In: LIMA, Diógenes Cândido de (org.). Ensino e aprendizagem de línguainglesa: conversas com especialistas. São Paulo: Parábola Editorial, 2009.

LEFFA, V. J. Aspectos políticos da formação do professor de línguas estrangeiras. In: LEFFA, Vilson J. (org.). O professor de línguas estrangeiras: construindo a profissão. Pelotas: $\quad$ EDUCAT, 2008. Disponível em <http://www.leffa.pro.br/textos/trabalhos/formacao.pdf>. Acesso em: 08 agost. 2017. Às 15:00.

MARTINEZ, P. Didática de línguas estrangeiras. São Paulo: Parábola Editorial, 2009.

NASCIMENTO, M, C. M. e BARBOSA, Raquel L. L. Formação inicial docente: o estágio como espaço de aprendizagens. Nuances: estudossobre Educação, Presidente Prudente-SP, v. 25, n. 3, p. 225-243, set./dez. 2014.

PIMENTA, S. G.; GHEDIN, Evandro (orgs). Professor reflexivo no Brasil: gênese e crítica de um conceito. São Paulo: Cortez, 2002

PIMENTA, S. G. Professor reflexivo: construindo uma crítica. In: PIMENTA, S. G.; GHEDIN (orgs). Professor reflexivo no Brasil: gênese e crítica de um conceito. 4. ed. São Paulo: Cortez, 2006.

Parâmetros Curriculares Nacionais (PCN) - Parâmetros de Língua Inglesa. Ensino Fundamental. Brasília: MEC/SEF. 1998.

PERRENOUD, P. Dez novas competências para ensinar. Porto Alegre: Artes Médicas Sul, 2000.

SILVA, L. C. da e MIRANDA, M. I. (Orgs.). Estágio supervisionado e prática de ensino: desafios e possibilidades. Araraquara, SP: Junqueira\&Marin; Belo Horizonte, MG: FAPEMIG, 2008.

SILVA, FAJARDO-TURBIN (orgs). Como Fazer Relatórios de Estágio Supervisionado: Formação de professores nas licenciaturas. Brasília: Liber Livro, 2012. 